NASZA DERMATOLOGIA Online OUR DERMATOLOGY Online

Source of Support:

Nil

Competing Interests:

None declared

\section{SOLITARY POROKERATOSIS OF MIBELLI AT AN UNUSUAL SITE}

Nithya Raghunath, Metikurke Vijayashankar

MVJ Medical College and Research Hospital, Bangalore, India

Corresponding author: Dr. Nithya Raghunath

\begin{abstract}
Porokeratosis is an assorted group of five genetic disorders. These include porokeratosis of Mibelli, DSAP, punctate porokeratosis, porokeratosis palmaris et plantaris disseminata, and linear porokeratosis. They are disorders of abnormal keratinization characterized by the appearance of atrophic patches. Porokeratosis of Mibelli is referred to the more localized form of this disorder usually manifesting as solitary or a small group of lesions. It was first described by Mibelli in 1893 who described atrophic patches surrounded by a clinically and histologically unique ridge like border termed the cornoid lamella. The cornoid lamella is formed by rapidly proliferating atypical keratinocytes that expands peripherally to form a raised boundary at the junction of abnormal and normal cells. These lesions are most commonly found on the extremities, but can also be found on genitalia, face, oral mucosa and cornea. Though the patches are generally asymptomatic they can often lead to ulcerative, verrucous, giant, and malignant lesions. We describe a case of Porokeratosis of Mibelli at an unusual site in a 22 yr old male. The presenting history, clinical findings, biopsy results and available literature are reviewed.
\end{abstract}

Key words: porokeratosis of mibelli; ala nasi; solitary $329-331$

\section{Introduction}

Porokeratosis is an assorted group of five genetic disorders. These include porokeratosis of Mibelli, DSAP, punctate porokeratosis, porokeratosis palmaris et plantaris disseminata, and linear porokeratosis [1]. They are disorders of abnormal keratinization characterized by the appearance of atrophic patches. Porokeratosis of Mibelli is referred to the more localized form of this disorder usually manifesting as solitary or a small group of lesions. It was first described by Mibelli in 1893 who described atrophic patches surrounded by a clinically and histologically unique ridge like border termed the cornoid lamella. The cornoid lamella is formed by rapidly proliferating atypical keratinocytes that expands peripherally to form a raised boundary at the junction of abnormal and normal cells. These lesions are most commonly found on the extremities, but can also be found on genitalia, face, oral mucosa and cornea [2]. Though the patches are generally asymptomatic they can often lead to ulcerative, verrucous, giant, and malignant lesions [3].

We describe a case of Porokeratosis of Mibelli at an unusual site in a $22 \mathrm{yr}$ old male. The presenting history, clinical findings, biopsy results and available literature are reviewed.

\section{Case Report}

A 22 year old male patient came with complaints of a white rash over his nose since 6 months. It was confined to the left ala of the nose (Fig. 1). The lesion started as a small papule and gradually spread peripherally. There was central clearing with hypo pigmentation and a raised border. The patient's history was otherwise insignificant. There was no similar history in the family. He was born of a non consanguineous marriage. There was no history suggestive of photosensitivity. His systemic examination was within normal limits. The differential diagnosis of Discoid Lupus Erythematoses, Basal Cell Carcinoma, Lupus Vulgaris and Porokeratosis were considered. Routine blood investigations were normal. HIV 1 and 2 was non reactive.

A full depth skin biopsy was taken from the outer part of the lesion with a $2 \mathrm{~mm}$ disposable skin biopsy punch and subjected to histopathology. The histopathology revealed foci of epidermal invagination filled with keratin and parakeratotic coronoid lamella. Dermis showed a mild to moderate infiltrate of lymphocytes (Fig. 2). On the basis of history, clinical examination and histopathology, a diagnosis of Porokeratosis of Mibelli was made. Topical tretinoin was prescribed for the management of the lesion. 


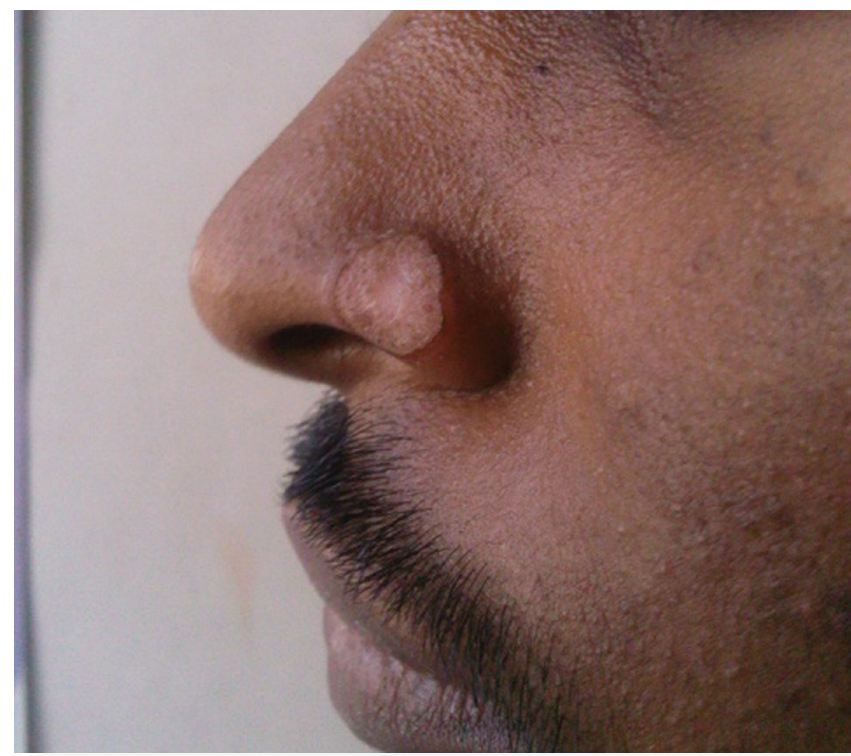

Figure 1. A single plaque with central clearing and a raised border over left ala of nose

\section{Discussion}

Porokeratosis of Mibelli may be familial, inherited as an autosomal dominant disorder with the onset in childhood or sporadic with later onset. Risk factors include immunosuppression, genetic inheritance, and UV radiation. The common underlying pathway in all forms of porokeratosis is a clonal hyperproliferation of atypical keratinocytes resulting in the characteristic cornoid lamella [4]. Histopathologic examination of a skin biopsy specimen from the area of suspicion is essential for diagnosis.

Porokeratosis of Mibelli is the most characteristic and distinctive variant of the five described forms of porokeratosis. The classical form of Mibelli consists of a single plaque, or a small number of plaques, of variable size and can affect any part of the body. Common areas involved are palms, soles and mucous membranes. Other areas of involvement reported include labial commisures, lips [5]. Histologically, the invaginations of the epidermis in Porokeratosis of Mibelli are wider and deeper, and there is prominent adjacent papillomatosis when compared with the other variants. All variants show a diminution of the granular layer, dilated superficial plexus capillaries, and a nonspecific superficial chronic infiltrate. Dermoscopy is also used in the diagnosis of porokeratosis [6].

The management of such lesions includes many options. The approach to treatment is individualized and based on many factors, such as lesion size and location, risk of malignant transformation, and functional and aesthetical considerations. Sun protection, emollients, and observation for signs of malignant degeneration are mandatory. Medical modalities focus on inhibiting cell growth and proliferation of the rapidly proliferating keratinocytes. Various modalities used include oral and topical retinoids, 5-fluorouracil cream, vitamin D3 analogues, diclofenac gel, imiquimod cream cryotherapy, dermabrasion and surgical excision. Recently photodynamic therapy has been shown to be an effective and safe alternative [7].

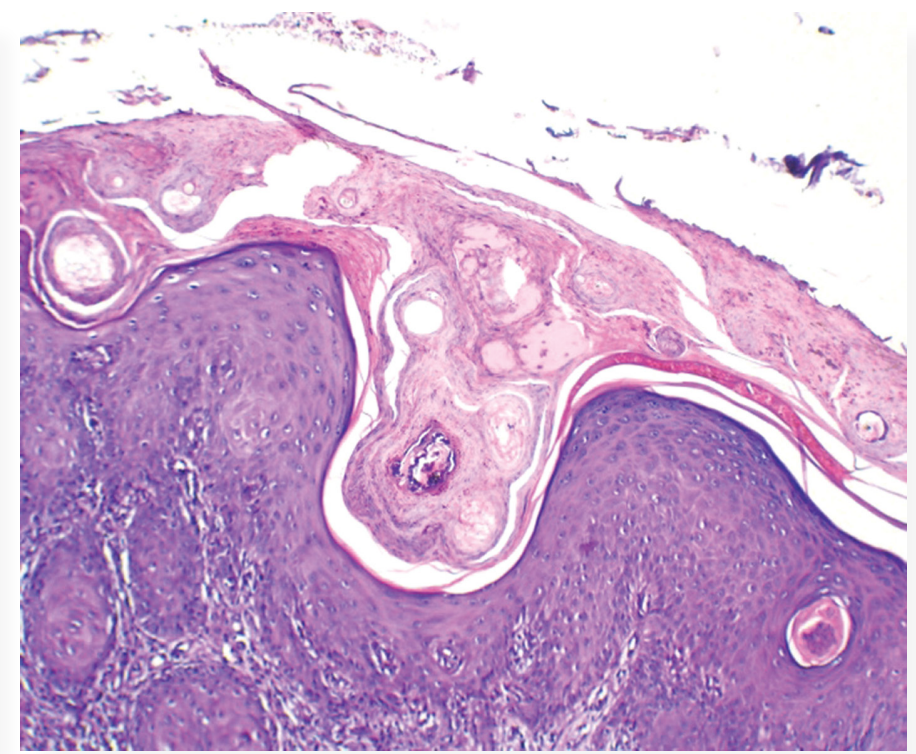

Figure 2. Histopathology (H\&E 45x) shows foci of epidermal invagination filled with keratin and parakeratotic coronoid lamella. Dermis shows a mild to moderate infiltrate of lymphocytes

\section{Conclusion}

A solitary Porokeratosis of Mibelli over the nose is uncommon. Such lesions may not always be clinically diagnosed, hence it requires histopathological examination. Hence Porokeratosis of Mibelli should be a differential diagnosis for any such plaques over nose.

Our case presented with a single lesion over the nose. This is a rare presentation. There are only two such cases which have been reported $[8,9]$.

\section{Acknowledgements}

Dr. Sujatha C, Prof. and Head Dept. of Dermatology, MVJ Medical College and Research Hospital.

Dr. Padmini Jeyachandran, Prof. and Head Dept. of Pathology, MVJ Medical College and Research Hospital.

Dr. Vasantha Kumar S, Principal, MVJ Medical College and Research Hospital.

\section{REFERENCES}

1. Ruiz Villaverde R, Alonso Corral MJ, Sa'nchez Cano D, Pacheco Sa' nchez-Lafuente FJ: [Linear porokeratosis of Mibelli]. An Pediatr (Barc). 2005;63:376-7.

2. Bacharach-Buhles M, Weindorf N, Altmeyer P: Porokeratosis Mibelli gigantea. Hautarzt. 1990;41:633-5.

3. Lin JH, Hsu MM, Sheu HM, Lee JY: Coexistence of three variants of porokeratosis with multiple squamous cell carcinomas arising from lesions of giant hyperkeratotic porokeratosis. J Eur Acad Dermatol Venereol. 2006;20:621-3.

4. Jurecka W, Neumann RA, Knobler RM: Porokeratoses: immunohistochemical, light and electron microscopic evaluation. J Am Acad Dermatol. 1991;24:96-101.

5. Vergara G, Bañuls J, Botella R, Silvestre JF, Belinchón I, Betlloch I: Porokeratosis of the lower lip. Eur J Dermatol. 2002;12:500-2. 6. Delfino M, Argenziano G, Nino M: Dermoscopy for the diagnosis of porokeratosis. J Eur Acad Dermatol Venereol. 2004;18:194-5. 
7. Levitt J, Emer JJ, Emanuel PO: Treatment of porokeratosis of Mibelli with combined use of photodynamic therapy and fluorouracil cream. Arch Dermatol. 2010;146:371-3.

8. Chaudhary RG, Bilimore F, Katare SK: Large annular plaque with central atrophy over nose. Indian J Dermatol Venerol Leperol. 2009;75:552.
9. Ghorpade A: Localized actinic nasal porokeratosis. Clin Exp Dermatol. 2010;35:211-2.

Copyright by Nithya Raghunath, et al. This is an open access article distributed under the terms of the Creative Commons Attribution License, which permits unrestricted use, distribution, and reproduction in any medium, provided the original author and source are credited. 